\title{
Exigência de proteína bruta para codornas européias no período de crescimento
}

[Crude protein requirement for European quails during the growing period]

\author{
A.B. Fridrich, B.D. Valente, A.S. Felipe-Silva, M.A. Silva*, G.S.S. Corrêa, D.O. Fontes, I.C. Ferreira \\ Escola de Veterinária da UFMG \\ Caixa Postal 567 \\ 30123-970 - Belo Horizonte, MG
}

\begin{abstract}
RESUMO
Estimou-se a exigência de proteína bruta para codornas européias de corte (Coturnix coturnix coturnix) nos períodos de 18-28, 28-42 e 42-56 dias de idade. O delineamento experimental foi inteiramente ao acaso, constituído de cinco tratamentos, seis repetições e 15 codornas por unidade experimental. As dietas experimentais foram formuladas com 18, 20, 22, 24 e $26 \%$ de proteína bruta e $2900 \mathrm{kCal} / \mathrm{kg}$ de energia metabolizável. As exigências de proteína bruta estimadas no período de 18-28 dias de idade para ganho de peso, conversão alimentar e peso corporal foram, respectivamente, 25,7; 25,2 e 25,5\%. De 28 a 42 dias de idade, a exigência de proteína bruta para peso corporal foi $24,6 \%$. Não houve efeito significativo do nível de proteína bruta sobre o ganho de peso e conversão alimentar nesse período. De 42 a 56 dias de idade, o efeito do nível de proteína bruta sobre o ganho de peso, conversão alimentar e peso corporal não foi significativo. Codornas européias de corte Coturnix coturnix coturnix apresentaram diminuição da exigência de proteína bruta para peso corporal no período $28-42$ dias de idade em comparação à exigência no período 18-28 dias de idade. Não foi possível estabelecer o requisito de proteína para peso corporal, ganho de peso e conversão alimentar após o $28^{\circ}$ dia de idade.
\end{abstract}

Palavras-chave: codorna, requerimento nutricional, proteína bruta

\begin{abstract}
A completely randomized design with five treatments and six replicates of 15 quails per experimental unity was used to estimate crude protein requirements for European quails (Coturnix coturnix coturnix) during the periods 18-28, 28-42 and 42-56 days of age. The experimental diets were formulated with 18, $20,22,24$, and $26 \%$ of crude protein and $2900 \mathrm{kcal} / \mathrm{kg}$ EM/ $/ \mathrm{kg}$. The protein requirements during $18-28$ days of age were respectively 25.7; 25.2 and $25.5 \%$ for weight gain, weight gain/feed intake ratio and for body weight. During the 28-42 period the crude protein requirement for body weight was $24.6 \%$, but there was no effect of crude protein level on weight gain and weight gain/feed intake ratio. The effect of crude protein level on weight gain, weight gain/feed intake ratio and body weight during 42-56 period was not significant. The European quails Coturnix coturnix coturnix have lower protein level requirement for body weight during 28-42 days of age in comparison to 18-28 period. No reliable estimates of crude protein requirements were obtained for body weight, weight gain and weight gain/feed intake ratio after 28 days of age.
\end{abstract}

Keywords: quail, nutritional requirement, crude protein

Recebido para publicação em 3 de maio de 2004

Recebido para publicação, após modificações, em 16 de dezembro de 2004

* Autor para correspondência (corresponding author)

E-mail: martinho@vet.ufmg.br 


\section{INTRODUÇÃO}

A produção e o consumo de ovos de codorna têm evoluído nos últimos anos, mas a criação de codornas para corte ainda enfrenta problemas de manejo, nutrição e sanidade. Eles resultam em perdas na produção e impossibilitam a expressão do potencial genético das aves (Bertechini, 2002).

Apesar da demanda, são escassas as pesquisas sobre exigências nutricionais de codornas européias (Coturnix coturnix coturnix) para as diversas fases da criação, assim como pesquisas sobre processamentos e embalagens que favoreçam a compra de carne de codorna.

O Nutrient... (1994) registra que não há novas informações a respeito da exigência nutricional de codornas desde 1984, o que demonstra a escassez de estudos sobre a espécie.
O objetivo deste trabalho foi estudar o efeito do nível de proteína sobre o peso final, ganho de peso, conversão alimentar e o consumo de ração de codornas européias em crescimento.

\section{MATERIAL E MÉTODOS}

Foram utilizadas 450 codornas européias de corte, não sexadas, em delineamento inteiramente ao acaso, com seis repetições de 15 aves por unidade experimental. Elas foram alimentadas com dietas experimentais contendo cinco diferentes níveis de proteína bruta $(18,20$, 22, 24 e $26 \%$ ) e nível constante de $2900 \mathrm{kcal} / \mathrm{kg}$ de ração. Os ingredientes e a composição das rações experimentais são apresentados na Tab. 1.

Tabela 1. Ingredientes e composição das diferentes dietas experimentais para codornas européias de corte

\begin{tabular}{|c|c|c|c|c|c|}
\hline \multirow{2}{*}{ Ingrediente } & \multicolumn{5}{|c|}{ Nível de proteína bruta (\%) } \\
\hline & 18 & 20 & 22 & 24 & 26 \\
\hline Milho & 66,793 & 60,309 & 53,797 & 47,274 & 40,762 \\
\hline Farelo de soja $45 \%$ & 25,503 & 30,989 & 36,494 & 42,005 & 47,510 \\
\hline Farelo de trigo & 4,000 & 4,000 & 4,000 & 4,000 & 4,000 \\
\hline Fosfato bicálcico & 1,008 & 0,980 & 0,951 & 0,923 & 0,895 \\
\hline Calcário & 1,154 & 1,132 & 1,109 & 1,087 & 1,064 \\
\hline Inerte (caulim) & 0,350 & 0,262 & 0,183 & 0,107 & 0,028 \\
\hline Sal comum & 0,281 & 0,276 & 0,271 & 0,266 & 0,261 \\
\hline Premix vitamínico mineral ${ }^{1}$ & 0,500 & 0,500 & 0,500 & 0,500 & 0,500 \\
\hline Óleo de soja & 0,411 & 1,465 & 2,528 & 3,595 & 4,658 \\
\hline DL-Metionina - 99\% & 0,000 & 0,048 & 0,095 & 0,141 & 0,187 \\
\hline L-Treonina - 98,5\% & 0,000 & 0,040 & 0,072 & 0,102 & 0,135 \\
\hline Total & 100,000 & 100,000 & 100,000 & 100,000 & 100,000 \\
\hline \multicolumn{6}{|c|}{ Composição química calculada } \\
\hline Proteína bruta (\%) & 18,000 & 20,000 & 22,000 & 24,000 & 26,000 \\
\hline E. metab. (Mcal/kg) & 2,900 & 2,900 & 2,900 & 2,900 & 2,900 \\
\hline Fósforo disp. (\%) & 0,300 & 0,300 & 0,300 & 0,300 & 0,300 \\
\hline Fósforo total (\%) & 0,535 & 0,546 & 0,558 & 0,570 & 0,581 \\
\hline Cálcio (\%) & 0,800 & 0,800 & 0,800 & 0,800 & 0,800 \\
\hline Gordura (\%) & 3,205 & 4,099 & 5,003 & 5,909 & 6,813 \\
\hline Lisina dig. aves $(\%)$ & 0,800 & 0,926 & 1,052 & 1,178 & 1,304 \\
\hline Lisina total $(\%)$ & 0,901 & 1,037 & 1,174 & 1,311 & 1,448 \\
\hline Metionina+cistina total $(\%)$ & 0,592 & 0,685 & 0,778 & 0,869 & 0,961 \\
\hline Metionina+cistina digestível aves (\%) & 0,518 & 0,606 & 0,692 & 0,778 & 0,863 \\
\hline Metionina digestível aves (\%) & 0,262 & 0,332 & 0,401 & 0,469 & 0,537 \\
\hline Metionina total (\%) & 0,388 & 0,460 & 0,532 & 0,602 & 0,672 \\
\hline Sódio (\%) & 0,150 & 0,150 & 0,150 & 0,150 & 0,150 \\
\hline Treonina digestível (\%) & 0,598 & 0,702 & 0,800 & 0,896 & 0,994 \\
\hline Treonina total $(\%)$ & 0,694 & 0,810 & 0,918 & 1,024 & 1,133 \\
\hline Triptofano digestível (\%) & 0,192 & 0,221 & 0,250 & 0,279 & 0,308 \\
\hline Triptofano total $(\%)$ & 0,214 & 0,246 & 0,277 & 0,309 & 0,341 \\
\hline
\end{tabular}

${ }^{1}$ Premix vitamínico e mineral por kg de ração: vit. A $3.750 .000 \mathrm{UI}$; vit. $\mathrm{D}_{3}, 750.000 \mathrm{UI}$; vit. E 7500mg; vit $\mathrm{K}_{3}$, 1.000mg; vit. $\mathrm{B}_{1}$, $750 \mathrm{mg}$; vit. $\mathrm{B}_{2}, 1.500 \mathrm{mg}$; vit. $\mathrm{B}_{6}, 1500 \mathrm{mg}$; vit. $\mathrm{B}_{12}, 7.500 \mathrm{mcg}$; vit. C $12.500 \mathrm{mg}$, biotina 30mg, niacina 10.000mg, ácido fólico 375; acid pantotênico $3.750 \mathrm{mg}$; colina $10.000 \mathrm{mg}$, metionina $400.000 \mathrm{mg}$, selênio $45 \mathrm{mg}$; iodo $175 \mathrm{mg}$; ferro $12.525 \mathrm{mg}$; cobre $2.500 \mathrm{mg}$; manganês, $19.500 \mathrm{mg}$; zinco $13.750 \mathrm{mg}$; prom. Prod $15.000 \mathrm{mg}$, coccidiostático $10.000 \mathrm{mg}$, antioxidante (B.H.T) $500 \mathrm{mg}$;

${ }^{2}$ A relação entre os aminoácidos baseou-se no Nutrient... (1994), com exceção da metionina, baseada em Pinto (2002). 
As aves foram criadas em baterias experimentais com $41 \times 82 \times 27 \mathrm{~cm}$, confeccionadas em arame galvanizado com comedouros internos de chapas galvanizadas, bebedouros de plástico com capacidade de um litro e dotadas de bandejas coletoras de fezes. A água e a ração foram fornecidas à vontade durante todo o período experimental. A iluminação artificial foi utilizada para completar 17 horas de luz por dia.

A ração fornecida foi armazenada em baldes plásticos de $20 \mathrm{~kg}$, identificados por tratamento e repetição para controle do consumo de alimento. Ao final de cada período experimental as codornas e as sobras nos cochos foram pesadas para registro de peso e cálculo do ganho de peso, do consumo de ração e da conversão alimentar.
As dietas experimentais foram formuladas para atender as exigências de crescimento de codornas estabelecidas pelo Nutrient requeriment of poultry (1994). A relação entre aminoácidos, com exceção da metionina, foi baseada nos resultados experimentais de Pinto (2002).

Os dados foram analisados utilizando o programa computacional SAEG (Sistema..., 1997)

\section{RESULTADOS E DISCUSSÃO}

O desempenho das codornas nos períodos 18-28, 28-42 e 42-56 dias de idade, de acordo com os níveis de proteína das dietas experimentais, é apresentado nas Tab. 2, 3 e 4.

Tabela 2. Desempenho de codornas no período 18-28 dias de idade de acordo com a dieta experimental

\begin{tabular}{lccccc}
\hline \multirow{2}{*}{ Característica } & \multicolumn{5}{c}{ Nível de proteína (\%) } \\
\cline { 2 - 6 } & 18 & 20 & 22 & 24 & 26 \\
\hline Peso final do lote $(\mathrm{g})^{1}$ & $2.408 \pm 44$ & $2.449 \pm 77$ & $2.585 \pm 35$ & $2.610 \pm 44$ & $2.652 \pm 47$ \\
Ganho/lote no período $(\mathrm{g})^{1}$ & $993 \pm 39$ & $1.036 \pm 68$ & $1.181 \pm 34$ & $1.194 \pm 51$ & $1.245 \pm 49$ \\
${\text { Conversão alimentar/lote }(\mathrm{kg} / \mathrm{kg})^{1}}^{1}$ & $4,07 \pm 0,55$ & $4,04 \pm 0,25$ & $3,40 \pm 0,33$ & $3,35 \pm 0,13$ & $3,18 \pm 0,22$ \\
Consumo de ração $(\mathrm{g})^{2}$ & $4.031 \pm 472$ & $4.179 \pm 105$ & $4.009 \pm 323$ & $4.004 \pm 178$ & $3.955 \pm 171$ \\
\hline
\end{tabular}

${ }^{1}$ Efeito significativo do nível de proteína na dieta $(\mathrm{P}<0,05)$.

${ }^{2}$ Efeito não significativo do nível de proteína na dieta $(\mathrm{P}>0,05)$.

Tabela 3. Desempenho de codornas no período 28-42 dias de idade de acordo com a dieta experimental

\begin{tabular}{|c|c|c|c|c|c|}
\hline \multirow{2}{*}{ Característica } & \multicolumn{5}{|c|}{ Nível de proteína (\%) } \\
\hline & 18 & 20 & 22 & 24 & 26 \\
\hline Peso final do lote $(\mathrm{g})^{1}$ & $3.536 \pm 174$ & $3.487 \pm 233$ & $3.794 \pm 114$ & $3.707 \pm 131$ & $3.753 \pm 183$ \\
\hline Ganho/lote no período $(\mathrm{g})^{2}$ & $1.128 \pm 159$ & $1.119 \pm 118$ & $1.208 \pm 85$ & $1.096 \pm 105$ & $1.101 \pm 154$ \\
\hline Conversão alimentar/lote $(\mathrm{kg} / \mathrm{kg})^{2}$ & $8,06 \pm 1,59$ & $8,33 \pm 1,00$ & $7,58 \pm 0,70$ & $8,55 \pm 0,67$ & $8,55 \pm 1,26$ \\
\hline Consumo de ração $(\mathrm{g})^{2}$ & $8.879 \pm 213$ & $9.104 \pm 1.01$ & $9.108 \pm 295$ & $9.324 \pm 475$ & $9.260 \pm 265$ \\
\hline
\end{tabular}

${ }^{1}$ Efeito significativo do nível de proteína na dieta $(\mathrm{P}<0,05)$.

${ }^{2}$ Efeito não significativo do nível de proteína na dieta $(\mathrm{P}>0,05)$.

Tabela 4. Desempenho de codornas no período 42-56 dias de idade de acordo com a dieta experimental

\begin{tabular}{|c|c|c|c|c|c|}
\hline \multirow{2}{*}{ Característica } & \multicolumn{5}{|c|}{ Nível de proteína (\%) } \\
\hline & 18 & 20 & 22 & 24 & 26 \\
\hline Peso final do lote $(\mathrm{g})^{1}$ & $3.747 \pm 141$ & $3.817 \pm 255$ & $3.954 \pm 194$ & $4.054 \pm 214$ & $4.063 \pm 323$ \\
\hline Ganho/lote no período $(\mathrm{g})^{1}$ & $299 \pm 53$ & $339 \pm 147$ & $252 \pm 89$ & $347 \pm 93$ & $353 \pm 129$ \\
\hline Conversão alimentar/lote $(\mathrm{kg} / \mathrm{kg})^{1}$ & $27,55 \pm 6,61$ & $21,41 \pm 4,91$ & $28,40 \pm 6,73$ & $25,31 \pm 5,85$ & $22,94 \pm 6,94$ \\
\hline Consumo de ração $(\mathrm{g})^{1}$ & $7.860 \pm 353$ & $7.982 \pm 311$ & $7.653 \pm 301$ & $8.345 \pm 404$ & $7.353 \pm 1173$ \\
\hline
\end{tabular}

${ }^{1}$ Efeito não significativo do nível de proteína na dieta $(\mathrm{P}<0,05)$.

O nível de proteína na ração influenciou $(\mathrm{P}<0,05)$ o peso corporal nos períodos $18-28$ e 28-42 dias de idade, o ganho de peso e a conversão alimentar no período 18-28 dias de idade.
Efeito significativo do nível de proteína sobre o peso corporal das codornas também foi observado em codornas japonesas (Coturnix coturnix japonica) por Pinto (2002), Sakuray (1981) e Shrivastav et al. (1993), cujos 
resultados indicaram que ao maior consumo de proteína correspondeu maior peso corporal das codornas. Kirkpinar e Oguz (1995), ao trabalharem com seis dietas protéicas com níveis de 16 a $30 \%$ de $\mathrm{PB}$, para codornas japonesas, verificaram rápido aumento na taxa de crescimento com o aumento do nível de proteína da dieta.

Houve efeito $(\mathrm{P}<0,05)$ do nível de proteína da dieta apenas sobre $\mathrm{o}$ índice de conversão alimentar no período 18-28 dias de idade. A não significância do nível de proteína sobre a eficiência alimentar nos períodos 28-42 e 42-56 pode ser explicada pelo fato de a conversão alimentar ser uma razão entre ganho de peso e consumo de alimento, visto que não foram influenciados pelo nível de proteína das dietas nos diversos períodos experimentais.

No período de 42-56 dias de idade observou-se elevado índice de conversão alimentar (Tab. 4). Resultados semelhantes foram também verificados por Oliveira (2002), principalmente em machos $(14,38 ; 12,99 ; 21,71 ; 13,72$ e 13,97 em dietas com 18,20, 22, 24 e $26 \%$ de proteína bruta, respectivamente) no período 38-49 dias de idade. Estes índices indicam que a velocidade de crescimento, nesse período, diminuiu, e tendeu a se estabilizar (peso). Nas fêmeas eles não foram tão altos.

A necessidade de se fazer adaptação nas baterias experimentais poderia explicar o elevado índice de conversão alimentar. Elas permitiram que as codornas tivessem livre acesso à parte interna dos comedouros, conseqüentemente, ao se alimentarem houve maior desperdício de ração. Contudo, o desperdício, apesar de não controlado, foi comum a todas as unidades experimentais.

As equações de regressão do peso corporal, ganho de peso e conversão alimentar em função do nível de proteína bruta da dieta, com os respectivos pontos que maximizam ou minimizam as variáveis analisadas, são apresentadas na Tab. 5 .

Tabela 5. Equações de regressão das características de desempenho em função do nível de proteína bruta da dieta

\begin{tabular}{cccccc}
$\begin{array}{c}\text { Período } \\
\text { (dias) }\end{array}$ & Variável & \multicolumn{1}{c}{ Equação de regressão } & $\begin{array}{c}\text { Ponto de } \\
\text { máximo }\end{array}$ & $\begin{array}{c}\mathrm{R}^{2} \\
\%\end{array}$ & $\begin{array}{c}\text { Significância } \\
(\mathrm{P})\end{array}$ \\
\hline $18-28$ & PLFP & $\hat{\mathrm{Y}}_{\mathrm{i}}=9,44160-1,06968 \mathrm{x}_{\mathrm{i}}+0,0525774 \mathrm{x}_{\mathrm{i}}{ }^{2}-0,000826389 \mathrm{x}_{\mathrm{i}}{ }^{3}$ & 25,48 & 77,5274 & 0.0000 \\
& GPLP & $\hat{\mathrm{Y}}_{\mathrm{i}}=6,29117-0,831653 \mathrm{x}_{\mathrm{i}}+0,0418021 \mathrm{x}_{\mathrm{i}}{ }^{2}-0,000664931 \mathrm{x}_{\mathrm{i}}{ }^{3}$ & 25,67 & 78,02 & 0.0000 \\
& CA & $\hat{\mathrm{Y}}_{\mathrm{i}}=-44,3959+7,04743 \mathrm{x}_{\mathrm{i}}-0.334604 \mathrm{x}_{\mathrm{i}}{ }^{2} 0,00515278 \mathrm{x}_{\mathrm{i}}{ }^{3}$ & $25,20^{*}$ & 55,59 & 0.0001 \\
$28-42$ & PLFP & $\hat{\mathrm{Y}}_{\mathrm{i}}=25,2193-3,14467 \mathrm{x}_{\mathrm{i}}+0,149473 \mathrm{x}_{\mathrm{i}}{ }^{2}-0,00231944 \mathrm{x}_{\mathrm{i}}{ }^{3}$ & 24,56 & 25,74 & 0.0485 \\
\hline
\end{tabular}

$\mathrm{PFP}=$ peso do lote ao final do período; $\mathrm{GLP}=$ ganho do lote no período; $\mathrm{CA}=$ conversão alimentar.

*Ponto de mínimo.

Os resultados das equações do peso corporal em cada período indicam que a dieta deve conter em torno de $25 \%$ de proteína bruta para que as codornas obtenham maior peso nos períodos 18 28 e 28-42 dias de idade. Vohra e Roudybush (1971), Vohra (1971) e Shirivastav e Panda (1991), citados por Shirivastav (2002), também verificaram que o nível adequado de PB na dieta de codornas japonesas em crescimento foi de $25 \%$.

À semelhança do observado por Oliveira (2000), os resultados indicam certa diminuição da exigência de proteína bruta após o $28^{\circ}$ dia de idade, para que codornas possam obter maior peso corporal. Shim e Vohra (1984) verificaram em codornas japonesas que, após a terceira semana de idade, o nível protéico podia ser reduzido de $28-32 \%$ no período de $1-14$ dias para $20 \%$ até a sexta semana de idade.

\section{CONCLUSÕES}

As exigências de proteína bruta estimadas para peso corporal, ganho de peso e conversão alimentar no período 18-28 dias de idade são, respectivamente, 25,$5 ; 25,7$ e $25,2 \%$ e para peso corporal no período $28-42$ dias de idade de $24,6 \%$. 


\section{REFERÊNCIAS BIBLIOGRÁFICAS}

KIRKPINAR, F.; OGUZ, I. Influence of various dietary protein levels on carcass composition in the male japanese quail (Coturnix coturnix japonica). Br. Poult. Sci., v.36, p.605-610, 1995.

NUTRIENT requirements of poultry. Washington: National Academic, 1994. p.44-45.

OLIVEIRA, N.T.E.; SILVA, M.A.; SOARES, R.T.R.N. et al. Exigências de proteína bruta e energia metabolizável para codornas japonesas criadas para a produção de carne. Rev. Bras. Zootec., v.31, p.675-686, 2002.

OLIVEIRA, N.T.E.; SILVA, M.A.; SOARES, R.T.R.N. et al. Exigências de proteína bruta e energia metabolizável para codornas japonesas machos criadas para a produção de carne. Arq. Bras. Med. Vet. Zootec., v.54, p.196-203, 2002.

PINTO, R.; FERREIRA, A.S.; ALBINO, L.F.T. et al. Níveis de proteína e energia para codornas japonesas em postura. Rev. Bras. Zootec.,v.31, p.1761-1770, 2002.

PINTO, R.; FERREIRA, A.S.; DONZELE, J.L. et al. Exigência nutricional em metionina + cistina para codornas japonesas em crescimento. In: REUNIÃO ANUAL DA SOCIEDADE BRASILEIRA DE ZOOTECNIA, 39., 2002, Recife, PE. Anais... Recife, SBZ, 2002.

SAKURAY, H. Influence of dietary levels of protein and energy on nitrogen and energy balance for egg production of Japanese quail. Jpn. Poult. Sci., v.18, p.185-192, 1981.

SHIM, K.F.; VORHA, P. A Review of the nutrition of Japanese quail. World's Poult. Sci. J., v.40, p.261-274, 1984.

SHRIVASTAV, A.K. Effect of age and diet on growth, meat quality and market possibilities of Japanese quail broilers. Indian Vet. Med. J. Anim. Sci., v.15, p.25-33, 1993.

SHRIVASTAV, A.K. Recentes avanços na nutrição de codornas japonesas. In: SIMPÓSIO INTERNACIONAL DE COTURNICULTURA Novos Conceitos Aplicados à Criação de Codornas, 2002, Lavras, MG. Anais... Lavras, 2002. p.67-75.

SISTEMA de análises estatísticas e genéticasSAEG. Versão 8.0. Viçosa, MG: UFV, 1997. 